\title{
Analysis of Fatigue and Crack Properties of High-Performance Concretes for Application in Nuclear Power Plants
}

\author{
Do-Gyeum Kim \\ Structural Engineering Research Institute \\ Korea Institute of Civil Engineering and Building Technology \\ Goyang, South Korea \\ E-mail:dgkim@kict.re.kr \\ Jang-Hwa Lee \\ Structural Engineering Research Institute \\ Korea Institute of Civil Engineering and Building Technology \\ Goyang, South Korea \\ E-mail: jhlee@kict.re.kr
}

\author{
Ho-Jae Lee \\ Structural Engineering Research Institute \\ Korea Institute of Civil Engineering and Building Technology \\ Goyang, South Korea \\ E-mail: h.lee@kict.re.kr \\ Eun-A Seo * \\ Structural Engineering Research Institute \\ Korea Institute of Civil Engineering and Building Technology \\ Goyang, South Korea \\ E-mail: sea0524@kict.re.kr
}

\begin{abstract}
The design of concrete structures used in nuclear power plants should be suitable to protect against accidents caused by different factors, one of them being temperature. Stress due to temperature can be classified as a secondary stress, which is different from the primary stress caused by an external load. This stress can create a bending moment as a result of a temperature gradient inside walls, which is caused by the difference of indoor and outdoor temperatures, or an axial force can be exerted depending on restraint conditions. In addition to seismic loads, the temperature load is a dominant factor in the design of concrete structures used in nuclear power plants considering their thickness should be at least $4 \mathrm{ft}$. to ensure radiation shielding. In particular, the tensile stress around large passing-through reinforced parts or the tensile strength at cylinder-foundation slab joints may induce concrete cracks at an early stage. Moreover, the use of high-strength concretes and rein-forced bars that can be designed with a relatively small amount of reinforced bars may lead to rapid reduction in rigidity after SSE. In addition, safety of nuclear power plant structures against accidents caused by high temperature and seismic loads is a mandatory permit and authorization issue that must be reviewed; moreover, the fatigue and crack properties of high-performance concretes must be determined. Thus, this study analyzed the fatigue and crack properties of high-performance concretes that can be used in nuclear power plants.
\end{abstract}

Keywords-HPC; Fatigue; Crack Property; Blast Furnace Slag; Fly Ash; Mineral Admixture;

\section{INTRODUCTION}

Concrete structures used in nuclear power plants should be designed to protect against various accidents and one of them is temperature. Similar to ACI 349-06, ACI 349-12 does not permit the use of structural plain concretes in nuclear power plant facilities for safety purposes. The minimum compressive strength of concretes has been increased from 2500 psi to 3000 psi. According to Section
6.3.14 in ACI 349-06, the temperature on the surface cannot exceed $150^{\circ} \mathrm{F}$ during normal operation and locally it cannot exceed $200^{\circ} \mathrm{F}$. According to ACI 349-12, if the actual test strength of the mix design concrete at age 28 days is higher than the design strength by $115 \%$ or larger, then the temperature criterion can be alleviated to $180^{\circ} \mathrm{F}$ and $230^{\circ} \mathrm{F}$ respectively [1].

In 1934, Lynam defined autogenous shrinkage as "a shrinkage differentiated from ones that occur due to moisture loss into temperature or the atmosphere". Following this, in 1940, Davis defined the autogenous shrinkage as a "phenomenon of changes in concrete volume as a result of changes in physicochemical structure inside the mass caused by other than stress due to moisture migration from the outside, temperature change, and external load or restraint". The technical committee on autogenous shrinkage of concrete at Japan Concrete Institute defined autogenous shrinkage as "volumetric reduction of binders that occurs when cements are hydrated after initial set" and specified that it did not include shrinkages due to loss or permeation of a substance, temperature change, and external load or restraint [2, 3].

In the regulations in ASME and SNB, there are no specific descriptions about concrete creep as well as no specific mention about fatigue in relation to the use permit of new materials. Thus, this study reviewed existing techniques used for evaluating concrete shrinkage. Subsequently, it evaluated the concrete autogenous shrinkage, drying shrinkage, and ring test according to high strengthening of concretes and use of various admixtures to acquire foundational data for required quality guarantee. To this end, we analyzed fatigue and crack properties of existing nuclear power plant mix $(6,000$ psi) and a standard mix of 8,000 psi and 10,000 psi prepared in this study. 


\section{FATIGUE PROPERTY OF HIGH-PERFORMANCE CONCRETES USED IN NUCLEAR POWER PlantS}

\section{A. Analysis of the Fatigue Behavior of Concretes}

The analysis of the fatigue behavior of concretes showed that although the fatigue properties of the structures were different depending on tension, compression, and shear stress, the structures were usually in a state of compressive stress for containment buildings; this is because they were compressed from all directions as a result of two-way pre-stressing

In a study by Kim et al., a fatigue experiment was performed with concretes of strengths $26,52,84$, and 103 MPa by applying repeated loads as shown in Figure 1(a); the results obtained are shown in Figure 1(b). As the magnitude of the maximum stress was increased, a failure occurred with a smaller number of repeated loads; moreover, as the concrete strength increased, the number of repeated loads tended to decrease [4].

However, considering the trend line in the experiment result, if a stress equal to $60 \%$ of the highest concrete strength of $103 \mathrm{MPa}$ is applied as the maximum stress of repeated loads, the concrete would not fracture below 105 $\mathrm{MPa}$ of repeated load. In general, the compressive stress applied to concretes under the service state of structures is less than $30 \%$ of the strength so that the probability of failure due to fatigue during the service period is very low.

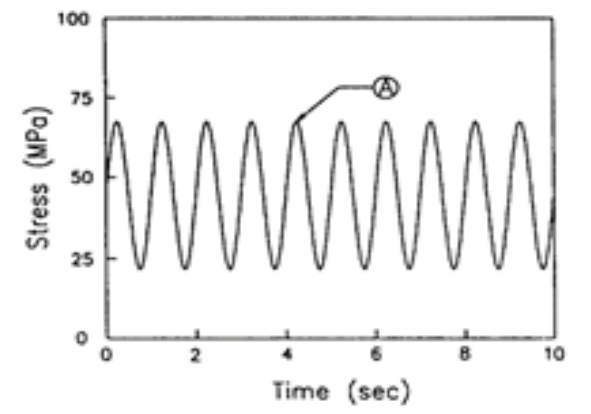

(a) Repeated Load

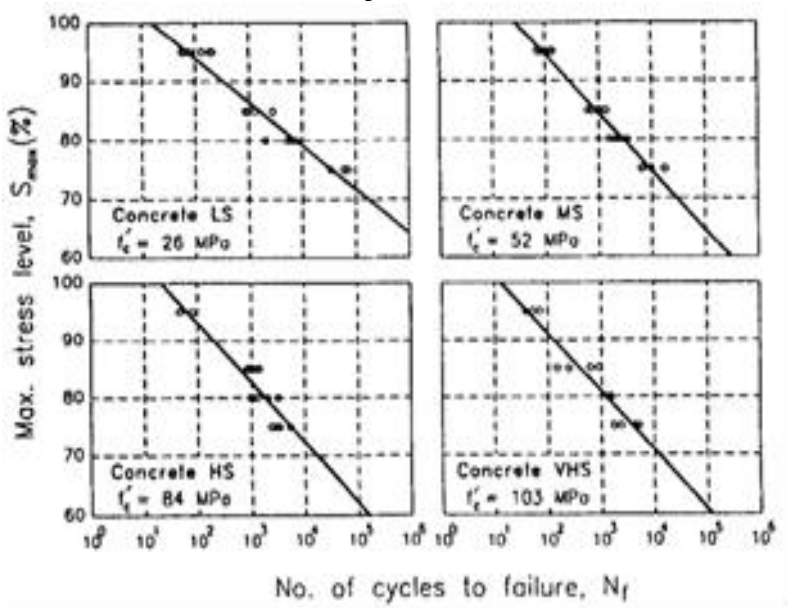

(b) Number of Repeated Loads during Failure Due to the Maximum Stress of the Repeated Load

FIGURE 1. FATIGUE PROPERTY ACCORDING TO CONCRETE STRENGTH (J.K. KIM, CCR, 1996)

\section{B. Fatigue Design of Concretes}

In reference to the concrete fatigue design regulation in Eurocode 2, in Eq. (1) represents fatigue strength; further, if calculated using Eq. (1) satisfies Eq. (6.77) shown in Figure 2, it was deemed appropriate for this study.

$$
f_{c d, f a t}=k_{1} \beta_{c o}\left(t_{0}\right) f_{c d}\left(1-\frac{f_{c k}}{250}\right)
$$

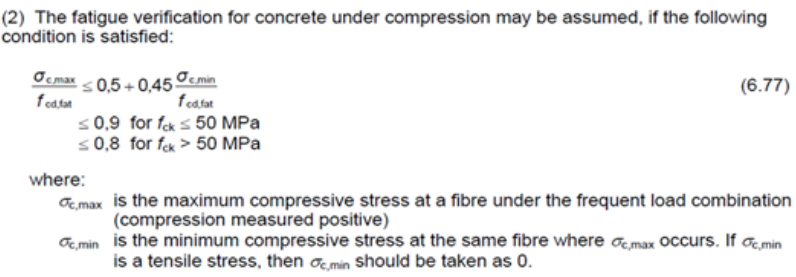

Figure 2. EUROCODE 2: FATIGUE DESIGN REGULATION OF PART 1 - 1

Figure 3 shows the number of repeated loads during the service period according to structure. For nu-clear power plants, at least 104 or smaller repeated loads are expected even with a conservative calculation. Even with the conservative assumption that the compressive stress applied to concretes is $30 \%$, it satisfied Eq. (1).

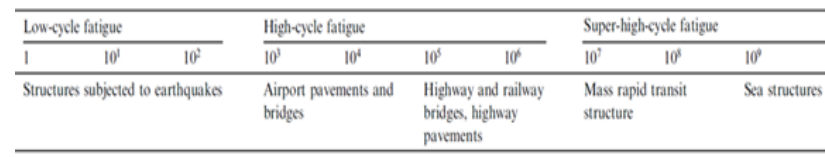

FIGURE. 3. NUMBER OF REPEATED LOADS DURING SERVICE PERIOD ACCORDING TO STRUCTURE

A part of the reports on evaluation of nuclear power plant structures by the IAEA mentioned about fatigue. Concretes have very high resistance against fatigue and show no fatigue failure in general. However, the report suggested that damage due to fatigue can occur around equipment or pipe supports. In the report, damages due to fatigue were investigated at 10 locations of real nuclear power plants; however, only one location developed cracks due to fatigue. Moreover, cracks were not found in containment buildings but in the internal structure.

\section{Analysis of Fatigue of HPC}

In the case of containment buildings of nuclear power plants, tensile stress is not exerted in all directions owing to two-way pre-stressing and the compressive stress actually exerted is evaluated as $30 \%$ or less of the actual strength. The number of repeated loads in the structures of nuclear power plants is not as large as that in other structures, and failure due to fatigue is not expected to occur according to our review of design methods or previous study results. With regard to HPC for new nuclear power plants, the compressive stress that is actually exerted is expected to be lower than $30 \%$ of the compressive stress. Under such circumstances, no experiment studies on fatigue are needed in particular. However, note that it is necessary to evaluate safety accurately in reference to previous studies on fatigue properties.

\section{ANALYSIS OF CRACK PROPERTIES}

\section{A. Experimental Design and Mixes}

The materials used in the experiment were as follows: Type 1 Portland cement, Type 2 fly ashes, Type 3 blast furnace slag and silica fume as binders; sea sand as fine 
aggregates; and ungraded crushed rock as coarse aggregates (maximum dimension: $20 \mathrm{~mm}$ ). Table 1 shows concrete mixes used in this study as experimental mixes. $6000-F A 20$ mixes with a goal strength of 6000 psi (41.36 $\mathrm{MPa}$ ) are those currently used for nuclear power plants and the other mixes are standard mixes with goal strengths of 8,000 psi (55.17 MPa) and 10,000 psi (68.97 MPa), respectively, prepared in this study

\section{B. Experimental Method}

Five specimens - three for compressive strength measurement and two for elastic modulus measurement were manufactured as per mix according to KS F 2403. Experiments were conducted in accordance with the KS F 2405 regulations.

TABLE 1. CONCRETE MIX DESIGN

\begin{tabular}{|c|c|c|c|c|c|c|c|c|c|}
\hline $\begin{array}{l}\text { Compressive } \\
\text { Strength } \\
\text { (psi) }\end{array}$ & Mix Type & $\mathrm{W} / \mathrm{C}$ & W & $\mathrm{C}$ & BS & FA & SF & S & G \\
\hline 6000 & FA20 & 40 & 162 & 324 & - & 81 & - & 747 & 963 \\
\hline \multirow{6}{*}{8000} & FA25 & \multirow{6}{*}{34} & 155 & 342 & - & 114 & - & 732 & 942 \\
\hline & BFS50 & & 155 & 228 & 228 & - & - & 742 & 956 \\
\hline & SF5 & & 155 & 433 & - & - & 23 & 735 & 942 \\
\hline & BS25FA25 & & 155 & 228 & 114 & 114 & - & 701 & 899 \\
\hline & BS30FA30 & & 155 & 182 & 137 & 137 & - & 696 & 893 \\
\hline & BS65SF5 & & 155 & 137 & 296 & - & 23 & 702 & 901 \\
\hline \multirow{6}{*}{10000} & SF5 & \multirow{6}{*}{28} & 155 & 526 & - & - & 28 & 710 & 914 \\
\hline & FA25SF5 & & 155 & 388 & - & 139 & 28 & 687 & 885 \\
\hline & BS30FA25SF5 & & 155 & 222 & 166 & 139 & 28 & 682 & 878 \\
\hline & BS45SF5 & & 155 & 277 & 249 & - & 28 & 702 & 904 \\
\hline & BS65SF5 & & 155 & 166 & 360 & - & 28 & 698 & 899 \\
\hline & BS25FA20SF5 & & 155 & 227 & 139 & 111 & 28 & 619 & 794 \\
\hline
\end{tabular}

For autogenous shrinkage measurements, an acryl mold as shown in Figure 4 was used as an improvement of the KS F 2586 regulation and two specimens were manufactured as per mix to measure changes in autogenous shrinkage. For drying shrinkage, experiments were conducted in accordance with the ASTM C 596 regulation and two specimens were manufactured as per mix to measure changes in drying shrinkage. For the ring test, cracks were measured after manufacturing specimens in accordance with the AASHTO T 334-08 (2012) regulation and potential for cracking was assessed according to ASTM C 1581/ C 1581M-09a [5-8].

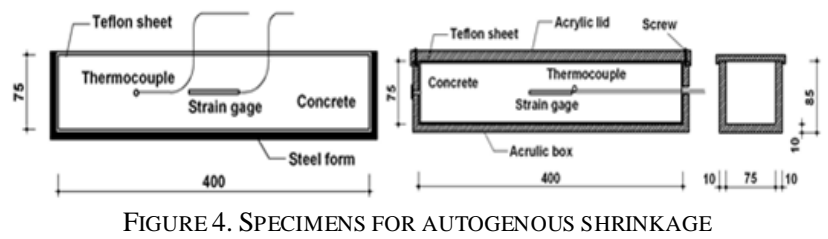

\section{Analysis Results of Crack Properties}

The test result of compressive strength and elastic modulus satisfied the goal strength in the design standards at age 91 days. In particular, a mix with 5\% SF showed the largest initial compressive strength. All standard mixes showed elastic moduli higher than that of the existing nuclear power plant mix (6,000 psi grade). In particular, all standard mixes had large initial elastic moduli up to age 7 days (Table 2).

\begin{tabular}{|c|c|c|c|c|c|c|c|c|}
\hline \multirow{2}{*}{$\begin{array}{l}\text { Goal } \\
\text { Strength } \\
\text { (psi) }\end{array}$} & \multirow[t]{2}{*}{ Mix } & \multirow{2}{*}{$\begin{array}{c}\text { Crack } \\
\text { Occurrenc } \\
\text { e } \\
\text { Time } \\
\text { (day) }\end{array}$} & \multirow{2}{*}{$\begin{array}{c}\text { No. } \\
\text { of } \\
\text { Crack } \\
\text { s }\end{array}$} & \multicolumn{2}{|c|}{$\begin{array}{l}\text { 91-Day } \\
\text { Crack } \\
\text { Width } \\
(\mathrm{mm})\end{array}$} & \multicolumn{3}{|c|}{$\begin{array}{l}\text { Assessment of } \\
\text { Potential Crack }\end{array}$} \\
\hline & & & & Max & Aver. & G & $\mathrm{S}$ & $\begin{array}{l}\text { Potential } \\
\text { for } \\
\text { Cracking }\end{array}$ \\
\hline 6000 & FA20 & 22 & 2 & 025 & $\begin{array}{l}0.1 \\
83\end{array}$ & 35.83 & 0.11 & $\begin{array}{c}\text { Moderate } \\
\text {-low }\end{array}$ \\
\hline \multirow{6}{*}{8,000} & FA25 & 50 & 3 & 050 & $\begin{array}{l}02 \\
76\end{array}$ & 35.83 & 0.05 & Low \\
\hline & BS50 & 70 & 2 & 0.10 & $\begin{array}{l}0.0 \\
68\end{array}$ & 35.83 & 0.05 & Low \\
\hline & SF5 & 12 & 3 & 030 & $\begin{array}{l}0.1 \\
46\end{array}$ & 35.83 & 0.13 & $\begin{array}{l}\text { Moderate- } \\
\text { highlow }\end{array}$ \\
\hline & BS25FA25 & 66 & 4 & 0.15 & $\begin{array}{l}0.0 \\
75\end{array}$ & 35.83 & 0.06 & Low \\
\hline & BS30FA30 & 85 & 2 & 0.08 & $\begin{array}{l}0.0 \\
42\end{array}$ & 35.83 & 0.05 & Low \\
\hline & BS65SF5 & after 91 & 1 & 0.15 & $\begin{array}{l}0.1 \\
20\end{array}$ & 35.83 & - & Low \\
\hline \multirow{6}{*}{10,000} & SF5 & 35 & 1 & 0.04 & $\begin{array}{l}0.0 \\
33\end{array}$ & 35.83 & 0.06 & Low \\
\hline & FA25SF5 & 10 & 2 & 030 & $\begin{array}{l}0.1 \\
63\end{array}$ & 35.83 & 0.14 & $\begin{array}{l}\text { Moderate- } \\
\text { highlow }\end{array}$ \\
\hline & BS30FA25SF5 & 36 & 2 & 0.06 & $\begin{array}{l}0.0 \\
40\end{array}$ & 35.83 & 0.05 & Low \\
\hline & BS45SF5 & 76 & 1 & 035 & $\begin{array}{l}02 \\
50\end{array}$ & 35.83 & 0.05 & Low \\
\hline & BS65SF5 & 29 & 1 & 030 & $\begin{array}{l}02 \\
02\end{array}$ & 35.83 & 0.08 & Low \\
\hline & BS25FA20SF5 & after91 & 1 & 0.40 & $\begin{array}{l}0.1 \\
96\end{array}$ & 35.83 & - & Low \\
\hline
\end{tabular}

For autogenous shrinkage, prediction equations of autogenous shrinkage of CEB, Tazawa, and Jonasson were compared. The experimental values for the standard mix of 8,000 psi grade were smaller than the predicted values for Tazawa and showed a similar trend as the predicted value for CEB. For the standard mix of 10,000 psi grade, the result was similar to or smaller than the predicted values for CEB and Jonasson, respectively, and was approximately half the predicted value for Tazawa [9$10]$.

\section{CONCLUSION}

In this study, the fatigue properties of highperformance concretes used in nuclear power plants were analyzed. For containment buildings in nuclear power plants, tensile stress was not exerted in all directions owing to two-way pre-stressing; further, compressive stress that was actually exerted was evaluated as $30 \%$ or less of the actual strength. Thus, the number of repeated loads in the nuclear power plant structures is lower than that of other structures; moreover, according to our review of the design method or previous study results, failure due to fatigue is not expected to occur. 
Furthermore, the effect of the admixture was larger than the effect of the water binder in terms of autogenous shrinkage, and shrinkage admixed with fly ashes was relatively smaller than mixes without fly ashes. In particular, mixes with a 5\% SF admixture increased autogenous shrinkage at an early age followed by expansion; for these mixes, the experimental values were similar to or smaller than the predicted values for CEB, Tazawa, and Jonasson. For drying shrinkage, the experimental values were small when the 5\% SF admixture was used and shrinkage crack reduction (below $-800 \mu \varepsilon$ ) was achieved to ensure durability defined in JASS5 by the Architectural Institute of Japan. The drying shrinkage values were similar to or larger than the predicted values for $\mathrm{CEB}, \mathrm{ACI}$, and $\mathrm{B} 3$.

\section{ACKNOWLEDGMENT}

This work was supported by the Nuclear Power R\&D Program of the Korea Institute of Energy Technology Evaluation and Planning (KETEP) grant funded by the Korea government Ministry of Knowledge Economy (No. 2014151010169A).

\section{REFERENCES}

[1] ACI 349, Code requirements for nuclear safety related concrete structures, 2006.
[2] Lura P., Durand F \& Jensen O.M. Autogenous strain of cement pastes with superabsorbent polymers, International RILEM Conference on Volume Changes of Hardening Concrete: Testing and Mitigation, 2006, pp.57-66.

[3] Kutti T., Berntsson L. and Chandra S. Shrinkage of cements with high content of blast furnace slag, in Malhotra, V. M. (Ed.), Proceedings of Fourth CANMET/ACI International Conference on Fly Ash, Slag and Natural Pozzolans in Concrete, 1992, pp. 615625.

[4] Kim J.-G. \& Kim Y.Y. Experimental study on fatigue behavior of high strength concretes, Proceedings of the Korea Concrete Institute Conference, Vol. 5, No. 4, 1993, pp. 177-187.

[5] ASTM Standard Test Method for chemical shrinkage of hydraulic cement paste, C1608-07, 2007.

[6] ASTM Standard Test Method for autogenous strain of hydraulic cement paste and mortar, C1608-09, 2009.

[7] Korea Industrial Standard, Cement Paste, Mortar, Test method of autogenous shrinkage and expansion of concretes, KS F 2586, 2010.

[8] Comité EuroInternational du Beton (CEB-FIP), Structural Concrete: Textbook on Behavior, Design and Performance, International Federation for Structural Concrete (Fib), 1999.

[9] ACI 209R-92. Prediction of creep, shrinkage, and temperature effects in concrete structures, ACI Manual of Concrete. Practice Part 1: Materials and General Properties of Concrete, 1994.

[10] Ojdrovic R. P. \& Zarghamee M. S. Concrete creep and shrinkage prediction from short term tests, ACI Materials Journal, 1996, Vol. 93, No. 2, pp. 169-177. 